\title{
Open or laparoscopic resection: does approach matter?
}

\author{
Ebru Esen ${ }^{1}$, Cihangir Akyol $^{2}$ \\ 'Department of General Surgery, Health Sciences University Konya Training and Research Hospital, Konya 42090, Turkey. \\ ${ }^{2}$ Department of General Surgery, Ankara University School of Medicine, Ankara 06230, Turkey.
}

Correspondence to: Dr. Cihangir Akyol, Department of General Surgery, Ankara University School of Medicine, Ankara, 06230 Turkey. E-mail: cihangirakyol@gmail.com

How to cite this article: Esen E, Akyol C. Open or laparoscopic resection: does approach matter? Mini-invasive Surg 2018;2:29. http://dx.doi.org/10.20517/2574-1225.2018.32

Received: 30 May 2018 First Decision: 9 Jul 2018 Revised: 14 Aug 2018 Accepted: 30 Aug 2018 Published: 26 Sep 2018

Science Editor: Gordon N. Buchanan Copy Editor: Cui Yu Production Editor: Huan-Liang Wu

\begin{abstract}
In colon cancer surgery, laparoscopic resection is a safer and more feasible method than open resection; however, despite its increasing popularity in recent years, laparoscopic approaches for the treatment of rectal cancer have not become a standard therapy option, due to the technical difficulties in gaining access to the deep and narrow pelvis and the steep learning curve. Multiple randomized trials found that short-term oncological outcomes and perioperative mortality and morbidity were comparable between laparoscopic and open rectal surgery, whereas comparative data between the two approaches. Comparative data between the two approaches on long-term oncological outcomes remain limited. In this review, we summarize the current status of laparoscopic surgery in rectal cancer in the light of recent studies.
\end{abstract}

Keywords: Laparoscopy, rectal cancer, oncological outcome, physiological outcome

\section{INTRODUCTION}

Colorectal cancer is one of the most commonly diagnosed cancers worldwide and is responsible for approximately 750,000 cancer-related deaths annually ${ }^{[1]}$. Approximately $30 \%$ of colorectal adenocarcinomas originate from the rectum. In a multidisciplinary approach that combines chemotherapy with radiotherapy for the treatment of colorectal cancer, surgery remains the primary treatment option. The most significant improvement in rectal surgery was the widespread implementation of the total mesorectal excision (TME) technique, first described by Heald et al. ${ }^{[2]}$ in 1982 , which led to a reduction in locoregional recurrence rates from $25 \%$ in the 1980 s to under $4 \%$ today ${ }^{[1]}$. 
The first successful use of laparoscopy in colorectal surgery was by Jacobs et al. ${ }^{[3]}$, published in 1991. Laparoscopic surgery has numerous benefits, such as shorter length of hospitalization, reduced postoperative pain, and improved recovery ${ }^{[4-6]}$. Although many studies showed that the outcomes of laparoscopic and open colon surgery were similar ${ }^{[6,7-10]}$, similar comparative outcomes have not been clearly demonstrated in laparoscopic rectal surgery. Concerns regarding laparoscopic rectal surgery are port-site and abdominal wall metastases and local oncological clearance ${ }^{[11-15]}$. In addition, laparoscopic rectal surgery has a challenging learning curve because of the deep and narrow pelvis and its assist-dependent procedure ${ }^{[16]}$.

Current data comparing long-term oncological outcomes between open and laparoscopic rectal surgery are insufficient; therefore, laparoscopy is not accepted as a gold standard in rectal surgery. This review aims to summarize the oncological and physiological outcomes with laparoscopic and open rectal surgery based on the results of recent studies.

\section{Importance of TME}

Significant improvements were observed in oncological outcomes with TME since its introduction by Heald et al. ${ }^{[2]}$ in 1982 and subsequent standardization in rectal cancer surgery. With the TME technique, the locoregional recurrence rate of $25 \%$ in the 1980 s has been successfully reduced to $4 \%$ currently. Nagtegaal and van Krieken ${ }^{[17]}$ reported that the local recurrence rate of $36 \%$ with incomplete mesorectal excision was decreased to $20 \%$ with complete TME. Kapiteijn et al ${ }^{[18]}$ compared the outcomes of conventional rectal surgery and TME and found that both local control and survival were improved in the TME group.

TME should be routinely performed to improve oncological results in both laparoscopic and open rectal surgery. Laparoscopic TME is a difficult technique to implement in the deep and narrow pelvis and has a steep learning curve. Several studies reported that at least 50 laparoscopic TME should be performed to achieve proficiency and consistent results ${ }^{[19-21]}$, and the conversion rate decreases between 151 and 200 cases. Male sex and T staging of cancer are major risk factors affecting the learning curve ${ }^{[14]}$. The most important concerns regarding laparoscopic TME are postoperative morbidity and oncological outcomes. One of the most important steps for the correct implementation of TME is dissection of the mesorectum from the parietal and visceral fascia. Laparoscopy provides visualization of this plan and neurovascular structures through a magnified and clean vision.

\section{Short-term oncological outcomes}

The use of TME for rectal cancer has led to many favorable results. Blunt dissection commonly performed in the pelvis before the TME era often resulted in inadequate resection of the mesorectum. Quirke et al. ${ }^{[22]}$ reported lateral surgical margin positivity in 14 of the 52 patients who achieved surgical cure and a local recurrence of $85 \%$ in those with positive margins. In contrast, in 1998, Heald et al. ${ }^{[23]}$ reported 5- and 10year local recurrence rates of only $3 \%$ and $4 \%$, respectively, among 405 patients who underwent curative resection with TME; the 5- and 10-year disease-free survival rates were $80 \%$ and $78 \%$, respectively, in this cohort. In a recent study by Maurer et al. ${ }^{[24]}$, where the patients were followed for a minimum of 7 years, TME reduced rectal cancer recurrence from $20.8 \%$ to $5.9 \%$.

Local recurrence is closely associated with several objectively measurable oncological parameters such as completeness of TME, involvement of the circumferential surgical margin (CRM), and number of harvested lymph nodes (HLNs). Prospective randomized trials included Colorectal Cancer Laparoscopic or Open Resection (COLOR) II trial, Conventional versus Laparoscopic-assisted Surgery in Patients with Colorectal Cancer (MRC CLASICC) trial, Open versus laparoscopic surgery for mid-rectal or low-rectal cancer after neoadjuvant chemoradiotherapy (COREAN) trial, ACOSOG Z6051 trial, Australian Laparoscopic Cancer of the Rectum (ALaCaRT) trial; retrospective studies, and meta-analyses evaluated the oncological outcomes of open and laparoscopic rectal surgery. In retrospective studies, laparoscopic rectal surgery was reported to be a generally safe and feasible procedure ${ }^{[25,26]}$. 
In the randomized COLOR II trial including 1103 patients with rectal cancer, although the duration of laparoscopic surgery was longer than that of open surgery ( $240 \mathrm{~min} v \mathrm{~s} .188 \mathrm{~min}$ ), blood loss was significantly less $(200 \mathrm{~mL} \text { vs. } 400 \mathrm{~mL} \text { ), and the length of hospital stay was shorter (8 days vs. } 9 \text { days })^{[27]}$. There were no significant differences in the rate of CRM positivity, number of HLNs, or distal surgical margins between the two groups.

In the CLASSIC trial that included 27 UK centers and 381 patients with rectal cancer were randomized to open $(n=128)$ and laparoscopic $(n=253)$ surgery groups ${ }^{[6]}$. The rate of conversion to open surgery was $34 \%$, whereas perioperative morbidity did not differ between the two groups. There was a nonsignificant increase in CRM positivity in the laparoscopic anterior resection group compared with the open surgery group $(12 \% v s .6 \%)$, suggesting a slight increase in the risk of recurrence. The 3- and 5-year follow-up studies of all rectal cancer patients revealed that there were no differences in local or distant recurrence rates between the laparoscopic and open surgical groups ${ }^{[28,29]}$.

In the COREAN trial including 340 patients with locally advanced rectal cancer (T3No-2) from three centers were randomized to open $(n=170)$ and laparoscopic surgery $(n=170)$ groups, and all patients received neoadjuvant chemoradiotherapy ${ }^{[30]}$. The rate of conversion to open surgery was $1.2 \%$, and no differences between the two groups were observed in terms of postoperative morbidity, mortality, CRM positivity, or TME quality.

The ACOSOG Z6051 trial recruited stage IIA or III rectal cancer patients with a tumor $\leq 12 \mathrm{~cm}$ from the anal verge after neoadjuvant therapy. The trial was powered to detect the noninferiority of laparoscopic surgery ${ }^{[31]}$. Conversion to open surgery occurred in $11.3 \%$ of the patients. The authors demonstrated that there were no differences in radial or distal margin positivity or complete or near-total TME between the laparoscopy and open surgery groups.

The design of ALaCaRT trial was similar to that of ACOSOG Z6051, recruiting T1-3 and No-2 rectal cancer patients with a tumor $\leq 15 \mathrm{~cm}$ from the anal verge to assess the noninferiority of laparoscopic surgery ${ }^{[10]}$. Although the length of laparoscopic surgery was longer, the blood loss was less in this group. There is no difference in the completeness of TME between the laparoscopic and open surgery groups ( $82 \% v s .89 \%)$, CRM positivity was observed in $7 \%$ and $3 \%$ of the laparoscopy and open surgery group patients, respectively $(P=0.06)$, and the rate of conversion to open surgery was $9 \%$. In this study, the laparoscopy group, especially those with large T3 tumors, failed to meet the noninferiority criteria. The controversy of this study with COREAN and COLOR II trials raised the question of whether there were any indications for laparoscopy in lower rectal cancers and locally advanced disease.

A prospective nonrandomized study by Lujan et al ${ }^{[32]}$ including 4405 patients from 72 centers who were divided into the laparoscopic $(n=1387)$ and open surgery $(n=3018)$ groups showed that the laparoscopy group had less hospitalization time, blood loss, and postoperative morbidity compared with the open surgery group. There was no significant difference in the number of HLNs between the two groups (laparoscopy vs. open, 14.5 vs. 14.7). The CRM and the distal margin involvement were significantly better in the laparoscopic group $(P<0.05)$, but the completeness of TME was significantly better in the open surgery group $(P$ $<0.05)$.

In a two-center prospective study by Ströhlein et al. ${ }^{[33]}$ laparoscopic surgery was associated with faster recovery and shorter hospital stays than open surgery. There is a significant difference in the number of HLNs between the laparoscopic and the open surgical groups (13.5 vs. 16.9; $P=0.001$ ); however, no differences local recurrence or metachronous metastasis were observed between the two groups.

In summary, these trials demonstrated that there were no differences in local tumor clearance, number of HLNs, or tumor recurrence rates between the two surgical approaches in patients with rectal cancer. 
Table 1. Randomized trials comparing oncological outcomes with laparoscopic and open surgery

\begin{tabular}{|c|c|c|c|c|c|}
\hline Study & $\begin{array}{l}\text { No. of patients } \\
\text { (L/O) }\end{array}$ & $\begin{array}{l}\text { Follow-up } \\
\text { (months) }\end{array}$ & $\begin{array}{c}\text { Local recurrence } \\
\text { (months) }(\mathrm{L} / \mathrm{O})(\%)\end{array}$ & $\begin{array}{c}\text { Overall survival } \\
\text { (months) }(\mathrm{L} / \mathrm{O})(\%)\end{array}$ & $\begin{array}{c}\text { Port site } \\
\text { recurrence (\%) }\end{array}$ \\
\hline Braga et $\left.a\right|^{[35]}$ & $83 / 85$ & 54 & $4 / 5.2$ & No difference & NA \\
\hline Jayne et $a l^{[28]}$ & $253 / 128$ & 56 & $9.4 / 7.6$ & $60 / 53$ (5 years) & 2.4 \\
\hline Green et $a l^{[36]}$ & $253 / 128$ & 63 & No difference & $\begin{array}{l}83 / 66 \text { months } \\
\text { (median overall survival) }\end{array}$ & NA \\
\hline Ng et al. ${ }^{[34]}$ & $40 / 40$ & 76 & $2.8 / 8.9$ & $86 / 91$ (5 years) & 0 \\
\hline Ng et al. ${ }^{[37]}$ & $51 / 48$ & 90 & $5 / 11$ & $75 / 77$ (5 years) & 0 \\
\hline
\end{tabular}

L: laparoscopy group; O: open surgery group; NA: not available

Laparoscopic TME for cancer is technically feasible, with acceptable complication rates and short-term oncological outcomes that are comparable with those of open surgery.

\section{Long-term oncological outcomes}

The few randomized trials comparing long-term outcomes after laparoscopic and open TME consistently reported that laparoscopic and open TME were associated with similar oncological outcomes ${ }^{[28,34-37]}$. A summary comparison of oncological outcomes between laparoscopic and open TME in randomized comparative trials are presented in Table $1^{[38]}$.

$\mathrm{Ng}$ et al ${ }^{[37]}$ investigated patients with rectal cancer who underwent laparoscopic $(n=51)$ or open abdominoperineal $(n=48)$ resection in a single-center prospective randomized trial. In this trial with a median follow-up duration of 90 months, the 5-year survival rates were $75.2 \%$ and $76.5 \%$ in the laparoscopic surgery and the open surgery groups, respectively. Another randomized trial in 2014, again by $\mathrm{Ng}$ et al. ${ }^{[34]}$, found that the 5 -year survival rates were $86 \%$ in the laparoscopic surgery group and $91 \%$ in the open surgery group during a median follow-up of 76 months. However, the number of patients receiving neoadjuvant treatment was not stated in neither of the studies; both of which included a relatively small number of patients. However, the results of both studies supported that the oncological outcomes of laparoscopic and open TME were comparable.

Bonjer et al. ${ }^{[9]}$ published the long-term results of the COLOR II trial in 2015. At the end of the 3-year follow-up, the disease-free survival rates of the laparoscopic and open surgery groups were $74.8 \%$ and $70.8 \%$, respectively, and there was no significant difference in overall survival between the laparoscopic and the open surgery groups ( $86.7 \%$ and $83.6 \%$, respectively). These results indicated that laparoscopic surgery was a suitable and valid method in rectal cancer that did not invade the surrounding tissues.

In the CLASSIC trial cohort, the 3-year overall survival rate of the laparoscopic surgery group was not worse than that of the open surgery group $(68.4 \% \text { and } 66.7 \% \text {, respectively, } P=0.55)^{[6]}$. There was also no statistically significant difference in disease-free survival between the two groups $(67.7 \%$ and $66.3 \%$ in open and laparoscopic surgery, respectively). The long-term results reported by Green et al. ${ }^{[36]}$ revealed that the median overall survival of patients who underwent surgery for rectal carcinoma was 73.6 months and that there were no significant differences in the median overall survival (82.7 and 65.8 months) or the diseasefree survival (67.1 and 70.6 months, $P=0.925$ ) between the open and laparoscopic surgery groups, respectively. Furthermore, there were no differences in local, wound, or port recurrent rates between the two groups. The authors concluded that laparoscopic surgery should be preferred for early functional recovery without adversely affecting long-term survival outcomes.

Evaluation of the 3-year disease-free survival rates of the COREAN trial found no difference between the open and laparoscopic surgery groups $(72.5 \%$ vs. $79.2 \%)$, and neither the 3-year overall survival nor the local recurrence parameters exceeded the $15 \%$ noninferiority limit ${ }^{[39]}$. 
A prospective study by Ströhlein et al. ${ }^{[33]}$ reported 5-year local recurrence rates of $6.9 \%$ and $9.5 \%$ with laparoscopic and open surgery, respectively. Additionally, there were no significant differences in 5-year survival rates based on the disease between the two groups (open $v s$. laparoscopic; stage I, $75.2 \% v s .85 .4 \%$; stage II, $73.4 \%$ vs. $66.7 \%$; stage III, $51.3 \%$ vs. 60.1\%). Similarly, Laurent et al ${ }^{[40]}$ found no significant differences in 5 -year local recurrence, disease-free survival, or overall survival rates between the laparoscopy and open surgery groups.

In summary, further randomized clinical trials are necessary for complete elucidation of the feasibility of laparoscopic surgery in rectal cancer. Additionally, the anticipated publication of the long-term results of the ACOSOG Z6051 and ALaCaRT trials should provide further insight regarding the implementation of laparoscopic surgery for rectal cancer.

\section{Sexual and urinary dysfunction associated with laparoscopic surgery}

Normal bladder and sexual function is controlled by sympathetic input from the superior hypogastric plexus and parasympathetic input from the pelvic splanchnic nerves, which are susceptible to injury during mesorectal resection. Injury to the sympathetic supply results in bladder instability and ejaculatory difficulties, whereas injury to the parasympathetic supply results in poor detrusor contraction and erectile dysfunction $^{[41,42]}$.

The incidence of urinary and sexual dysfunction after open TME is significantly high ${ }^{[43-46]}$. In laparoscopic TME, preservation of the nerves can be achieved by magnifying the images. In a series of 274 patients reported by Runkel and Reiser ${ }^{[4]}$, only $1.8 \%$ of the patients required prolonged urinary catheterization postoperatively. In other studies, the rate of urinary dysfunction after laparoscopic TME ranged from 6\% to $15 \%{ }^{[48-52]}$, and the incidence of dysfunction ranged between $5 \%$ and $28 \%$ in males who were sexually active before laparoscopic $\mathrm{TME}^{[34,47,51,52]}$.

Asoglu et al. ${ }^{[52]}$ reported that the rate of reduction in sexual function among female patients was $7 \%$. In that comparative study, laparoscopic TME was associated with significantly less sexual dysfunction in both male and female patients, and the rate of urinary dysfunction was similar between the laparoscopic and open TME groups.

In a study on data from 247 patients enrolled in the CLASSIC trial, Jayne et al ${ }^{[4]]}$ reported that the rate of bladder dysfunction was similar between the open and laparoscopic surgery groups; however, the rate of erectile dysfunction was higher in the laparoscopic surgery group, which was attributed to the higher frequency of TME in the laparoscopic surgery group.

In their prospective randomized trial, $\mathrm{Ng}$ et al.$^{[34]}$ found that there was no significant difference in urinary or erectile dysfunction between the laparoscopic and open TME groups. In the COREAN trial, however, there were significantly fewer urinary complications in the laparoscopic surgery group ${ }^{[39]}$. Relatedly, McGlone et al. ${ }^{[53]}$ compared patients undergoing proctectomy by laparoscopic and open surgeries. Urinary and sexual dysfunction was observed in both surgery groups; however, penetration success in males and sexual activity results in women were found to be better in the laparoscopy group.

Overall, the results of these studies indicate that there was no major difference in urinary or sexual dysfunction between patients undergoing laparoscopic and open rectal surgery and that the main causes of these complications were rectal resection and TME, not the surgical approaches.

\section{DISCUSSION}

The development of minimally invasive colorectal surgery has been the greatest technological advance 
in colorectal surgery in the past 20 years, with established benefits in short-term outcomes and return to function. Laparoscopic rectal surgery can promote patient recovery, overall outcome, and quality of life. Appropriate training is essential to achieve results that are at least comparable with oncological results. Most importantly, the concerns and controversies regarding oncological outcomes with laparoscopic TME should be resolved with the publication of the results of the studies evaluating long-term survival with this surgical approach.

\section{CONCLUSION}

TME, which should be performed to preserve the nerves and ureters, is technically difficult to perform in the pelvis. The surrounding tissues can be visualized more clearly with the laparoscopic approach; however, the angulation of the laparoscopic instruments and endoscopic staples is limited. Therefore, at least 50 laparoscopic rectal surgeries must be performed to achieve proper experience with this technique. The results of the studies published to date reveal that there is no difference in short-term outcomes between the laparoscopic and open approach. The long-term results of the limited number of trials conducted to date reported that the outcomes were similar between the two surgical groups; however, concerns remain regarding the utility of laparoscopy in locally advanced and distal rectal cancer, which should be addressed by evaluating long-term outcomes with additional randomized controlled trials.

\section{DECLARATIONS}

\section{Authors' contributions}

Both authors contributed to the conception and the design of the review.

\section{Availability of data and materials}

Not applicable.

\section{Financial support and sponsorship}

None.

\section{Conflict of interest}

All authors declared that there are no conflicts of interest.

\section{Ethical approval and consent to participate}

Not applicable.

\section{Consent for publication}

Not applicable.

\section{Copyright}

(c) The Author(s) 2018.

\section{REFERENCES}

1. Nienhüser H, Heger P, Schmitz R, Kulu Y, Diener MK, Klose J, Schneider M, Müller-Stich BP, Ulrich A, Büchler MW, Mihaljevic AL, Schmidt T. Short- and long-term oncological outcome after rectal cancer surgery: a systematic review and meta-analysis comparing open versus laparoscopic rectal cancer surgery. J Gastrointest Surg 2018;22:1418-33.

2. Heald RJ, Husband EM, Ryall RD. The mesorectum in rectal cancer surgery--the clue to pelvic recurrence? Br J Surg 1982;69:613-6.

3. Jacobs M, Verdeja JC, Goldstein HS. Minimally invasive colon resection (laparoscopic colectomy). Surg Laparosc Endosc 1991;1:14450.

4. Clinical Outcomes of Surgical Therapy Study Group, Nelson H, Sargent DJ, Wieand HS, Fleshman J, Anvari M, Stryker SJ, Beart RW Jr, Hellinger M, Flanagan R Jr, Peters W, Ota D. A comparison of laparoscopically assisted and open colectomy for colon cancer. N Engl J Med 2004;350:2050-9.

5. Veldkamp R, Kuhry E, Hop WC, Jeekel J, Kazemier G, Bonjer HJ, Haglind E, Påhlman L, Cuesta MA, Msika S, Morino M, Lacy AM; 
Colon cancer Laparoscopic or Open Resection Study Group (COLOR). Laparoscopic surgery versus open surgery for colon cancer: short-term outcomes of a randomised trial. Lancet Oncol 2005;6:477-84.

6. Guillou PJ, Quirke P, Thorpe H, Walker J, Jayne DG, Smith AM, Heath RM, Brown JM; MRC CLASICC trial group. Short-term endpoints of conventional versus laparoscopic-assisted surgery in patients with colorectal cancer (MRC CLASICC trial): multicentre, randomised controlled trial. Lancet 2005;365:1718-26.

7. Fleshman J, Sargent DJ, Green E, Anvari M, Stryker SJ, Beart RW Jr, Hellinger M, Flanagan R Jr, Peters W, Nelson H; Clinical Outcomes of Surgical Therapy Study Group. Laparoscopic colectomy for cancer is not inferior to open surgery based on 5-year data from the COST study group trial. Ann Surg 2007;246:655-62.

8. Lacy AM, Delgado S, Castells A, Prins HA, Arroyo V, Ibarzabal A, Pique JM. The long-term results of a randomized clinical trial of laparoscopy-assisted versus open surgery for colon cancer. Ann Surg 2008;248:1-7.

9. Bonjer HJ, Deijen CL, Abis GA, Cuesta MA, van der Pas MH, de Lange-de Klerk ES, Lacy AM, Bemelman WA, Andersson J, Angenete E, Rosenberg J, Fuerst A, Haglind E; COLOR II Study Group. A randomized trial of laparoscopic versus open surgery for rectal cancer. N Engl J Med 2015;372:1324-32.

10. Stevenson AR, Solomon MJ, Lumley JW, Hewett P, Clouston AD, Gebski VJ, Davies L, Wilson K, Hague W, Simes J; ALaCaRT Investigators. Effect of laparoscopic-assisted resection vs open resection on pathological outcomes in rectal cancer: the ALaCaRT randomized clinical trial. JAMA 2015;314:1356-63.

11. Wexner SD, Cohen SM. Port site metastases after laparoscopic colorectal surgery for cure of malignancy. Br J Surg 1995;82:295-8.

12. Nduka CC, Monson JR, Menzies-Gow N, Darzi A. Abdominal wall metastases following laparoscopy. Br J Surg 1994;81:648-52.

13. Milsom JW, Fazio VW. Concerns about laparoscopic colon cancer surgery. Dis Colon Rectum 1994;37:625-6.

14. Zmora O, Gervaz P, Wexner SD. Trocar site recurrence in laparoscopic surgery for colorectal cancer. Surg Endosc 2001;15:788-93.

15. Silecchia G, Perrotta N, Giraudo G, Salval M, Parini U, Feliciotti F, Lezoche E, Morino M, Melotti G, Carlini M, Rosato P, Basso N; Italian Registry of Laparoscopic Colorectal Surgery. Abdominal wall recurrences after colorectal resection for cancer: results of the Italian registry of laparoscopic colorectal surgery. Dis Colon Rectum 2002;45:1172-7.

16. Cima RR, Pattana-arun J, Larson DW, Dozois EJ, Wolff BG, Pemberton JH. Experience with 969 minimal access colectomies: the role of hand-assisted laparoscopy in expanding minimally invasive surgery for complex colectomies. J Am Coll Surg 2008;206:946-50.

17. Nagtegaal ID, van Krieken JH. The role of pathologists in the quality control of diagnosis and treatment of rectal cancer-an overview. Eur J Cancer 2002;38:964-72.

18. Kapiteijn E, Putter H, van de Velde CJ; Cooperative investigators of the Dutch ColoRectal Cancer Group. Impact of the introduction and training of total mesorectal excision on recurrence and survival in rectal cancer in the Netherlands. Br J Surg 2002;89:1142-9.

19. Kayano H, Okuda J, Tanaka K, Kondo K, Tanigawa N. Evaluation of the learning curve in laparoscopic low anterior resection for rectal cancer. Surg Endosc 2011;25:2972-9.

20. Park IJ, Choi GS, Lim KH, Kang BM, Jun SH. Multidimensional analysis of the learning curve for laparoscopic colorectal surgery: lessons from 1,000 cases of laparoscopic colorectal surgery. Surg Endosc 2009;23:839-46.

21. Li JC, Hon SS, Ng SS, Lee JF, Yiu RY, Leung KL. The learning curve for laparoscopic colectomy: experience of a surgical fellow in an university colorectal unit. Surg Endosc 2009;23:1603-8.

22. Quirke P, Durdey P, Dixon MF, Williams NS. Local recurrence of rectal adenocarcinoma due to inadequate surgical resection. Histopathological study of lateral tumour spread and surgical excision. Lancet 1986;2:996-9.

23. Heald RJ, Moran BJ, Ryall RD, Sexton R, MacFarlane JK. Rectal cancer: the Basingstoke experience of total mesorectal excision, 1978-1997. Arch Surg 1998;133:894-9.

24. Maurer CA, Renzulli P, Kull C, Käser SA, Mazzucchelli L, Ulrich A, Büchler MW. The impact of the introduction of total mesorectal excision on local recurrence rate and survival in rectal cancer: long-term results. Ann Surg Oncol 2011;18:1899-906.

25. Boutros M, Hippalgaonkar N, Silva E, Allende D, Wexner SD, Berho M. Laparoscopic resection of rectal cancer results in higher lymph node yield and better short-term outcomes than open surgery: a large single-center comparative study. Dis Colon Rectum 2013;56:67988.

26. Lee SD, Park SC, Park JW, Kim DY, Choi HS, Oh JH. Laparoscopic versus open surgery for stage I rectal cancer: long-term oncologic outcomes. World J Surg 2013;37:646-51.

27. van der Pas MH, Haglind E, Cuesta MA, Fürst A, Lacy AM, Hop WC, Bonjer HJ; COlorectal cancer Laparoscopic or Open Resection II (COLOR II) Study Group. Laparoscopic versus open surgery for rectal cancer (COLOR II): short-term outcomes of a randomised, phase 3 trial. Lancet Oncol 2013;14:210-8.

28. Jayne DG, Thorpe HC, Copeland J, Quirke P, Brown JM, Guillou PJ. Five-year follow-up of the Medical Research Council CLASICC trial of laparoscopically assisted versus open surgery for colorectal cancer. Br J Surg 2010;97:1638-45.

29. Jayne DG, Guillou PJ, Thorpe H, Quirke P, Copeland J, Smith AM, Heath RM, Brown JM; UK MRC CLASICC Trial Group. Randomized trial of laparoscopic-assisted resection of colorectal carcinoma: 3-year results of the UK MRC CLASICC trial group. J Clin Oncol 2007;25:3061-8

30. Kang SB, Park JW, Jeong SY, Nam BH, Choi HS, Kim DW, Lim SB, Lee TG, Kim DY, Kim JS, Chang HJ, Lee HS, Kim SY, Jung KH, Hong YS, Kim JH, Sohn DK, Kim DH, Oh JH. Open versus laparoscopic surgery for mid or low rectal cancer after neoadjuvant chemoradiotherapy (COREAN trial): short-term outcomes of an open-label randomised controlled trial. Lancet Oncol 2010;11:637-45.

31. Fleshman J, Branda M, Sargent DJ, Boller AM, George V, Abbas M, Peters WR Jr, Maun D, Chang G, Herline A, Fichera A, Mutch M, Wexner S, Whiteford M, Marks J, Birnbaum E, Margolin D, Larson D, Marcello P, Posner M, Read T, Monson J, Wren SM, Pisters PW, Nelson H. Effect of laparoscopic-assisted resection vs open resection of stage II or III rectal cancer on pathologic outcomes: the ACOSOG Z6051 randomized clinical trial. JAMA 2015;314:1346-55.

32. Lujan J, Valero G, Biondo S, Espin E, Parrilla P, Ortiz H. Laparoscopic versus open surgery for rectal cancer: results of a prospective multicentre analysis of 4,970 patients. Surg Endosc 2013;27:295-302. 
33. Ströhlein MA, Grützner KU, Jauch KW, Heiss MM. Comparison of laparoscopic vs. open access surgery in patients with rectal cancer: a prospective analysis. Dis Colon Rectum 2008;51:385-91.

34. Ng SS, Lee JF, Yiu RY, Li JC, Hon SS, Mak TW, Ngo DK, Leung WW, Leung KL. Laparoscopic-assisted versus open total mesorectal excision with anal sphincter preservation for mid and low rectal cancer: a prospective, randomized trial. Surg Endosc 2014;28:297-306.

35. Braga M, Frasson M, Vignali A, Zuliani W, Capretti G, Di Carlo V. Laparoscopic resection in rectal cancer patients: outcome and costbenefit analysis. Dis Colon Rectum 2007;50:464-71.

36. Green BL, Marshall HC, Collinson F, Quirke P, Guillou P, Jayne DG, Brown JM. Long-term follow-up of the Medical Research Council CLASICC trial of conventional versus laparoscopically assisted resection in colorectal cancer. Br J Surg 2013;100:75-82.

37. Ng SS, Leung KL, Lee JF, Yiu RY, Li JC, Teoh AY, Leung WW. Laparoscopic-assisted versus open abdominoperineal resection for low rectal cancer: a prospective randomized trial. Ann Surg Oncol 2008;15:2418-25.

38. Meng WCS, Cheung HYS, Lam DTY, Ng SSM. Minimally invasive coloproctology: advances in techniques and technology. Cham: Springer; 2015. p. 157-9.

39. Jeong SY, Park JW, Nam BH, Kim S, Kang SB, Lim SB, Choi HS, Kim DW, Chang HJ, Kim DY, Jung KH, Kim TY, Kang GH, Chie EK, Kim SY, Sohn DK, Kim DH, Kim JS, Lee HS, Kim JH, Oh JH. Open versus laparoscopic surgery for mid-rectal or low-rectal cancer after neoadjuvant chemoradiotherapy (COREAN trial): survival outcomes of an open-label, non-inferiority, randomised controlled trial. Lancet Oncol 2014;15:767-74.

40. Laurent C, Leblanc F, Wütrich P, Scheffler M, Rullier E. Laparoscopic versus open surgery for rectal cancer: long-term oncologic results. Ann Surg 2009;250:54-61.

41. Jayne DG, Brown JM, Thorpe H, Walker J, Quirke P, Guillou PJ. Bladder and sexual function following resection for rectal cancer in a randomized clinical trial of laparoscopic versus open technique. Br J Surg 2005;92:1124-32.

42. Keating JP. Sexual function after rectal excision. ANZ J Surg 2004;74:248-59.

43. Havenga K, Enker WE, McDermott K, Cohen AM, Minsky BD, Guillem J. Male and female sexual and urinary function after total mesorectal excision with autonomic nerve preservation for carcinoma of the rectum. J Am Coll Surg 1996;182: 495-502.

44. Kapiteijn E, Marijnen CA, Nagtegaal ID, Putter H, Steup WH, Wiggers T, Rutten HJ, Pahlman L, Glimelius B, van Krieken JH, Leer JW, van de Velde CJ; Dutch Colorectal Cancer Group. Preoperative radiotherapy combined with total mesorectal excision for resectable rectal cancer. N Engl J Med 2001;345:638-46.

45. Saito N, Sarashina H, Nunomura M, Koda K, Takiguchi N, Nakajima N. Clinical evaluation of nerve-sparing surgery combined with preoperative radiotherapy in advanced rectal cancer patients. Am J Surg 1998;175:277-82.

46. Kim NK, Aahn TW, Park JK, Lee KY, Lee WH, Sohn SK, Min JS. Assessment of sexual and voiding function after total mesorectal excision with pelvic autonomic nerve preservation in males with rectal cancer. Dis Colon Rectum 2002;45:1178-85.

47. Runkel N, Reiser H. Nerve-oriented mesorectal excision (NOME): autonomic nerves as landmarks for laparoscopic rectal resection. Int J Colorectal Dis 2013;28:1367-75.

48. Motson RW, Khan JS, Arulampalam TH, Austin RC, Lacey N, Sizer B. Laparoscopic total mesorectal excision following long course chemoradiotherapy for locally advanced rectal cancer. Surg Endosc 2011;25:1753-60.

49. Maglio R, Meucci M, Muzi MG, Maglio M, Masoni L. Laparoscopic total mesorectal excision for ultralow rectal cancer with transanal intersphincteric dissection as a first step: a single-surgeon experience. Am Surg 2014;80:26-30.

50. Morino M, Parini U, Allaix ME, Monasterolo G, Brachet Contul R, Garrone C. Male sexual and urinary function after laparoscopic total mesorectal excision. Surg Endosc 2009;23:1233-40.

51. Jones OM, Stevenson AR, Stitz RW, Lumley JW. Preservation of sexual and bladder function after laparoscopic rectal surgery. Colorectal Dis 2009;11:489-95.

52. Asoglu O, Matlim T, Karanlik H, Atar M, Muslumanoglu M, Kapran Y, Igci A, Ozmen V, Kecer M, Parlak M. Impact of laparoscopic surgery on bladder and sexual function after total mesorectal excision for rectal cancer. Surg Endosc 2009;23:296-303.

53. McGlone ER, Khan O, Flashman K, Khan J, Parvaiz A. Urogenital function following laparoscopic and open rectal cancer resection: a comparative study. Surg Endosc 2012;26:2559-65. 